Bull. Mater. Sci., Vol. 21, No. 6, December 1998, pp. 493-497. (C) Indian Academy of Sciences.

\title{
Micro hardness measurements on lead silicate glass
}

\author{
V K SHRIKHANDE, T MIRZA, B B SAWANT, A K SINHA ${ }^{\dagger}$ and G P KOTHIYAL* \\ Technical Physics and Prototype Engineering Division, ${ }^{\dagger}$ Atomic Fuel Division, Bhabha Atomic Research Centre, \\ Mumbai 400085 , India \\ MS received 25 March 1998; revised 24 August 1998
}

\begin{abstract}
The synthesis of lead silicate glass suitable for fabrication of compression type glass to metal seals has been studied with varying amounts of modifier ions ( $\mathrm{Na}, \mathrm{K}$ and $\mathrm{Ba}$ ). $A$ three-stage heating schedule was evolved for the preparation of glass. While, some of the constituents were taken in the form of oxides, the others were either in the form of carbonates or nitrates. Dependence of micro hardness of these glasses on the relative content of $\mathrm{Na}_{2} \mathrm{O}, \mathrm{K}_{2} \mathrm{O}$ and $\mathrm{BaO}$ was investigated. The concentration of these oxides was varied in the range $0-16 \mathrm{wt} \%$. The modifier ions were seen to affect the micro hardness in a complex manner. While the micro hardness of glass without $\mathrm{Na}_{2} \mathrm{O}$ and $13 \mathrm{wt} \% \mathrm{~K}_{2} \mathrm{O}$ was found to be $504 \mathrm{~kg} / \mathrm{mm}^{2}$, it turned out to be $547 \mathrm{~kg} / \mathrm{mm}^{2}$ for a glass with $13 \mathrm{wt} \%$ of $\mathrm{Na}_{2} \mathrm{O}$ in the absence of $\mathrm{K}_{2} \mathrm{O}$. However, the micro hardness of the glass synthesized having optimum composition with oxides of $\mathrm{Na}, \mathrm{K}$ and $\mathrm{Ba}$ in the proportion of 5,8 and $4 \mathrm{wt} \%$, respectively was $455 \mathrm{~kg} / \mathrm{mm}^{2}$. The glass powder was found to be suitable for making single- and multi-pin seals which could withstand pressures up to $1.2 \times 10^{4}$ psi and vacuum of $10^{-8}$ Torr.
\end{abstract}

Keywords. Micro hardness measurement; lead silicate glass.

\section{Introduction}

Lead silicate glasses find applications in the detection of gamma rays (Wiza 1979; Mckee et al 1988), ultrasonic delay cables (Tashiro and Okuda 1987), electron multiplier (Anderson et al 1979), TV picture tubes (Thomas and Sircer 1987), glass to metal (GM) seals (Bandhopadhyay et al 1989; Donald 1993), etc. While for these applications, either glass with a lower processing temperature may be required or its expansion coefficient has to be matched with another solid, for some other applications a glass having higher density or refractive index may be required. It is therefore necessary to modify the physical properties of the silica glass. This has been achieved through the introduction of a large number of various oxides into random network of $\mathrm{SiO}_{2}$. The devitrification of glass plays a crucial role in the selection of various oxide ions (Muller et al 1993). Among other ions, the role of lead ions in $\mathrm{SiO}_{2}$ matrix has been studied recently in some detail (Liu 1993; Wang and Zhang 1996). Wang and Zhang (1996) have also shown that in the glasses containing $\mathrm{Pb}$ ion concentration greater than $40 \mathrm{~mol} \%, \mathrm{PbO}$ assumes the role of main glass former. However, the presence of lower amounts of $\mathrm{PbO}$ has the effect of lowering the melting point and viscosity of silica, while its density and refractive index are increased. Though the general procedure for making glass

*Author for correspondence is available in literature, the information available on the effect of the processing parameters and the usefulness of a particular glass composition for a specific end use is often incomplete. The mechanical strength of glass is an important parameter determining its suitability for certain applications such as glass to metal (GM) seals. It is now well established that micro hardness provides a convenient tool for studying the brittleness of solids (Tabor 1996) and softening point of the glass (Holland 1966).

In this paper, we have reported the synthesis and characterization of soft glass (lead silicate) powder suitable for the fabrication of compression type GM seals. The effect of the relative contents of $\mathrm{Na}_{2} \mathrm{O}, \mathrm{K}_{2} \mathrm{O}$ and $\mathrm{BaO}$ on the micro hardness and sealing characteristics of the $\mathrm{Pb}$-silicate glass has been studied. The content of these oxides was varied from 0 to $16 \mathrm{wt} \%$. Increase in the $\mathrm{Na}_{2} \mathrm{O}$ concentration relative to that of $\mathrm{K}_{2} \mathrm{O}$ was found to increase the micro hardness of the glass and also introduced bubbles in the GM seals fabricated, using such powders.

\section{Experimental}

The process followed for the synthesis of glass powder involved grinding, mixing and a three-stage heating cycle. This is a modified procedure compared to that reported earlier (Shrikhande et al 1997, 1998). In order to prepare the initial charge, about $54 \mathrm{wt} \%$ of silica was mixed with the nitrates or carbonates of $\mathrm{Na}, \mathrm{K}$ and $\mathrm{Ba}$ and 


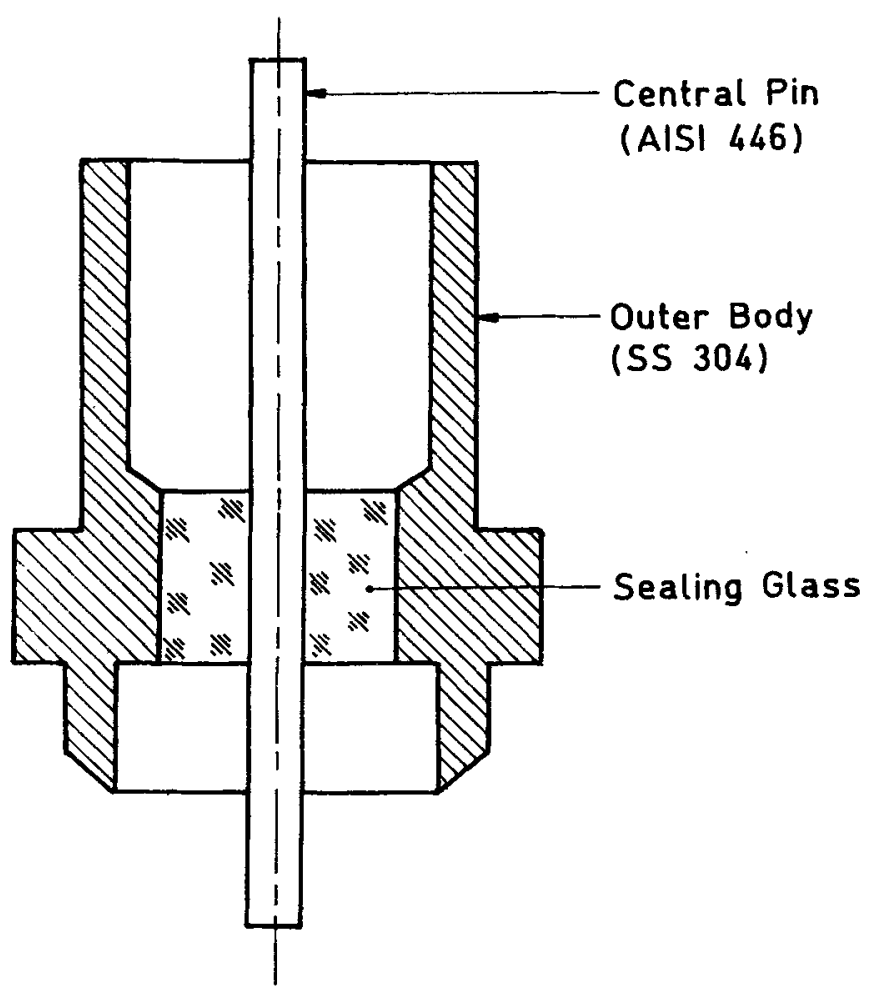

Figure 1. Schematic of a compression type glass to metal seal. pulverized in a planetary ball mill (PM 4000, Retsch, Germany) for $2-3 \mathrm{~h}$. The mixture was subjected to a slow heating up to $750^{\circ} \mathrm{C}$, where it was maintained for a period of $30-40 \mathrm{~h}$ in the first stage followed by thorough grinding and mixing. It was then heated to about $950^{\circ} \mathrm{C}$ for calcination. In the final stage of glass formation, about $32 \mathrm{wt} \%$ of $\mathrm{PbO}$ was mixed with the calcined material and the charge was raised to around $1300^{\circ} \mathrm{C}$. Subsequently, it was fast cooled for glass formation. The temperature was brought to $600^{\circ} \mathrm{C}$ within $2.5 \mathrm{~h}$ and then furnace was switched off. To investigate the effect of the relative contents of $\mathrm{Na}, \mathrm{K}$ and $\mathrm{Ba}$ on micro hardness and the sealing characteristics of the $\mathrm{Pb}$-silicate glass, initial charges containing different amounts of $\mathrm{NaNO}_{3}, \mathrm{KNO}_{3}$ and $\mathrm{Ba}\left(\mathrm{NO}_{3}\right)_{2}$ were taken, while those of $\mathrm{SiO}_{2}$ and $\mathrm{PbO}$ were kept the same. Of course, the total content of $\mathrm{Na}_{2} \mathrm{O}, \mathrm{K}_{2} \mathrm{O}$ and $\mathrm{BaO}$ in the glass did not exceed $17 \mathrm{wt} \%$.

XRD patterns for the glass powders synthesized were recorded on DIANO 2000 series X-ray diffractometer. For micro hardness measurements, the glass samples prepared from nitrates were first embedded in bakalite mounts and then polished with diamond paste. The measurements were done on Wilson Tukon 300 model with a maximum load of $200 \mathrm{~g}$ and objective magnifi-

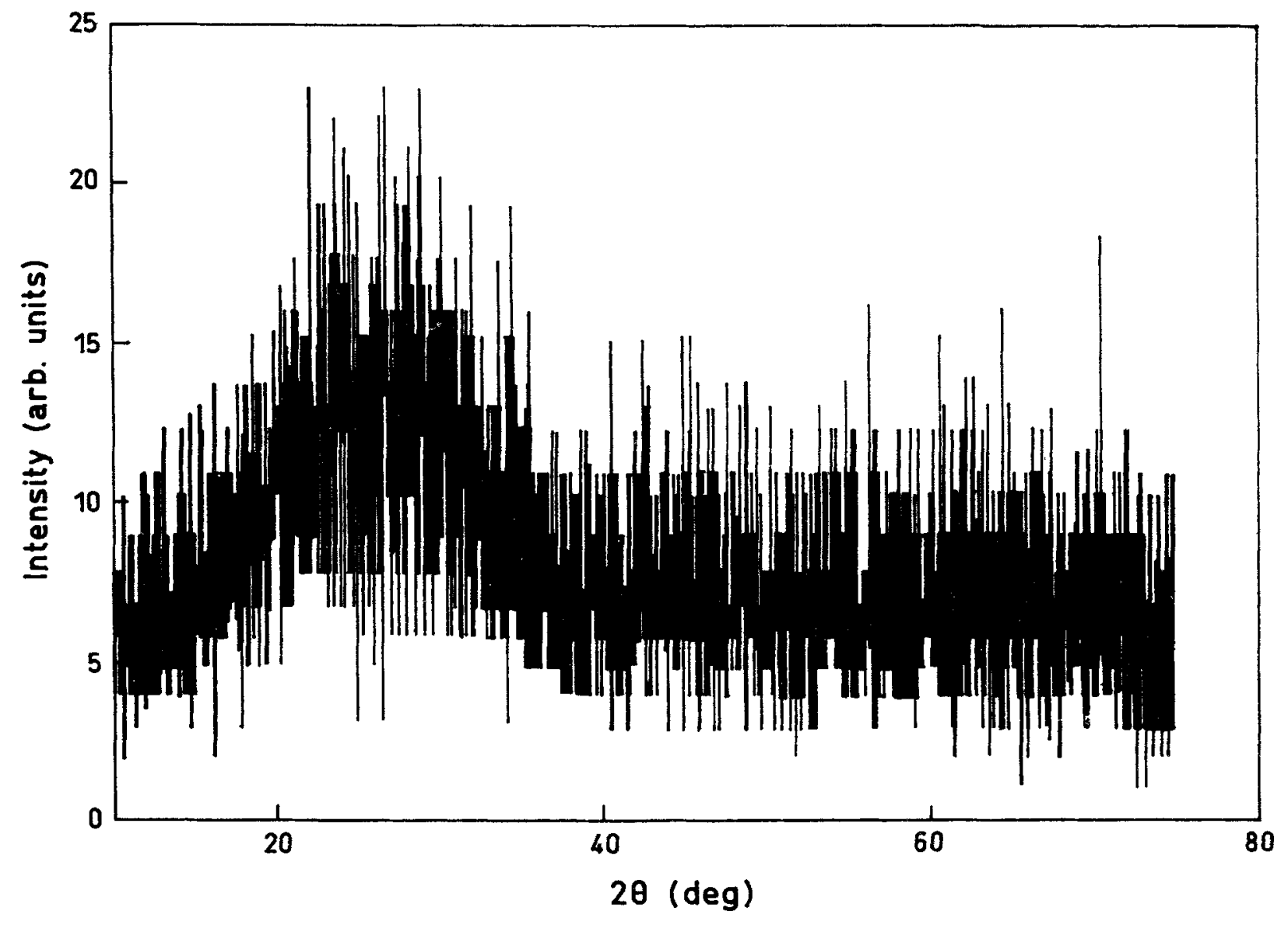

Figure 2. XRD pattern of lead silicate glass powder. 
cation of $10 \times$. An average of at least four observations for each sample was taken.

Single-pin and multi-pins compression type GM seals were fabricated to test suitability of the glass powders synthesized for this purpose. Figure 1 shows the construction of a single-pin seal. The seal consisted of an outer stainless steel body with thermal expansion coefficient greater than that of glass powder and a central pin of AISI $446 \mathrm{Cr}-\mathrm{Fe}$ alloy. The expansion coefficient of glass was matched with that of the central pin. For the fabrication of seal, glass powder of about $10 \mu \mathrm{m}$ size was used to prepare a preform by following the usual procedure of compaction of powder in suitable die and high temperature sintering. All the metal parts were fired in hydrogen ambient at high temperature prior to growing an oxide layer of controlled thickness. The metal parts and glass preform were assembled in vertical position in a graphite jig. The entire assembly was heated to glass melting temperature in a predetermined manner and under nitrogen ambient, using an rf induction heater. During cooling operation, the seal was annealed around $500^{\circ} \mathrm{C}$ for a period of $1 \mathrm{~h}$. For making multi-pin seals, required modifications as regards to size, pin arrangement etc were carried out in the preform making and other holding jigs and fixtures.

The vacuum leak testing of the seals was carried out using a mass spectrometer leak detector. In order to carry out high pressure test, the seal was mounted on a special jig, enabling measurement up to $1.2 \times 10^{4} \mathrm{psi}$.

\section{Results and discussion}

All the glass samples of optimized composition were observed to be colourless, transparent and bubble free. The XRD measurements brought out the glassy nature of the samples. A typical XRD plot is shown in figure 2 .

Results of micro hardness measurement on lead silicate glass having varying amounts of $\mathrm{Na}, \mathrm{K}$ and $\mathrm{Ba}$ ions are shown in figures $3-5$. Figures $3 \mathrm{~A}$ and $\mathrm{B}$ show the variation of micro hardness of the glass as a function of $\mathrm{K}_{2} \mathrm{O}$ concentration in presence (A) and absence (B) of $\mathrm{Na}_{2} \mathrm{O}$. It is seen that the micro hardness of $\mathrm{K}_{2} \mathrm{O}$ glass (B) increases initially with $\mathrm{K}_{2} \mathrm{O}$ concentration up to $8 \mathrm{wt} \%$ and then shows a decreasing trend at higher concentrations. However, when $5 \mathrm{wt} \%$ of $\mathrm{Na}_{2} \mathrm{O}$ is present in the glass (A), micro hardness first decreases to a minimum of $455 \mathrm{~kg} / \mathrm{mm}^{2}$ and subsequently shows an increasing trend. Increase in micro hardness is associated with the increase in softening temperature (Holland 1966). The variation of micro hardness with $\mathrm{Na}_{2} \mathrm{O}$ in presence (A) and absence (B) of $\mathrm{K}_{2} \mathrm{O}$ is shown in figures $4 \mathrm{~A}$ and $\mathrm{B}$. In glass without $\mathrm{K}_{2} \mathrm{O}$, micro hardness continues to increase rapidly with $\mathrm{Na}_{2} \mathrm{O}$ content up to $13 \mathrm{wt} \%$ used in the present study. But in presence of $8 \mathrm{wt} \% \mathrm{~K}_{2} \mathrm{O}$, the micro hardness first decreases and then increases in a manner similar to samples without $\mathrm{K}_{2} \mathrm{O}$ content.

Addition of $\mathrm{BaO}$ in glass with $5 \mathrm{wt} \% \mathrm{Na}_{2} \mathrm{O}$ and $8 \mathrm{wt} \%$ $\mathrm{K}_{2} \mathrm{O}$ in varying amounts changes the micro hardness of the glass (figure 5). There is initially a decrease in the

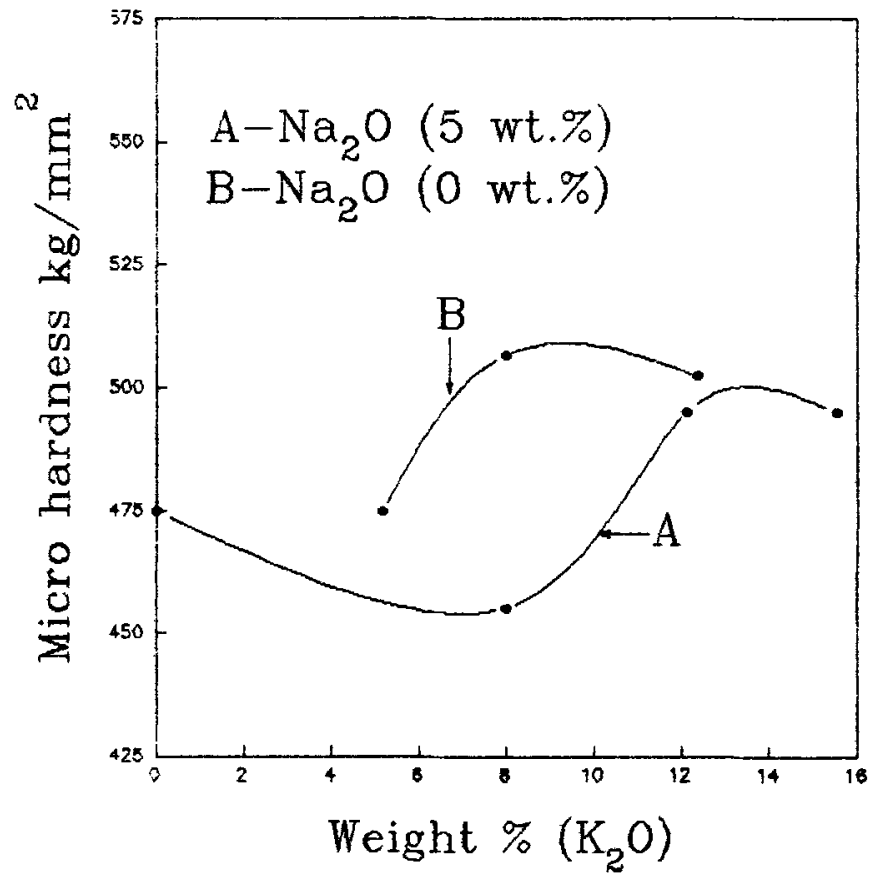

Figure 3. Micro hardness as a function of $\mathrm{K}_{2} \mathrm{O}$ content: (A) in presence of $5 \mathrm{wt} \% \mathrm{Na}_{2} \mathrm{O}$ and $(\mathrm{B})$ in absence of $\mathrm{Na}_{2} \mathrm{O}$.

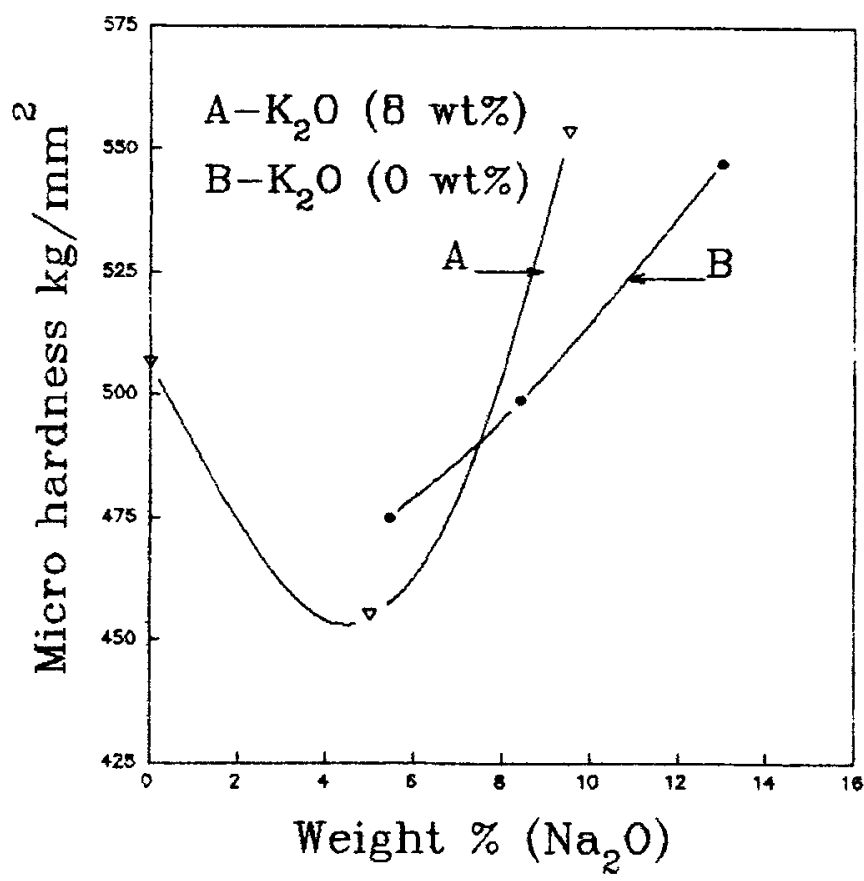

Figure 4. Micro hardness as a function of $\mathrm{Na}_{2} \mathrm{O}$ content: (A) in presence of $8 w t \% \mathrm{~K}_{2} \mathrm{O}$ and $(\mathrm{B})$ in absence of $\mathrm{K}_{2} \mathrm{O}$. 


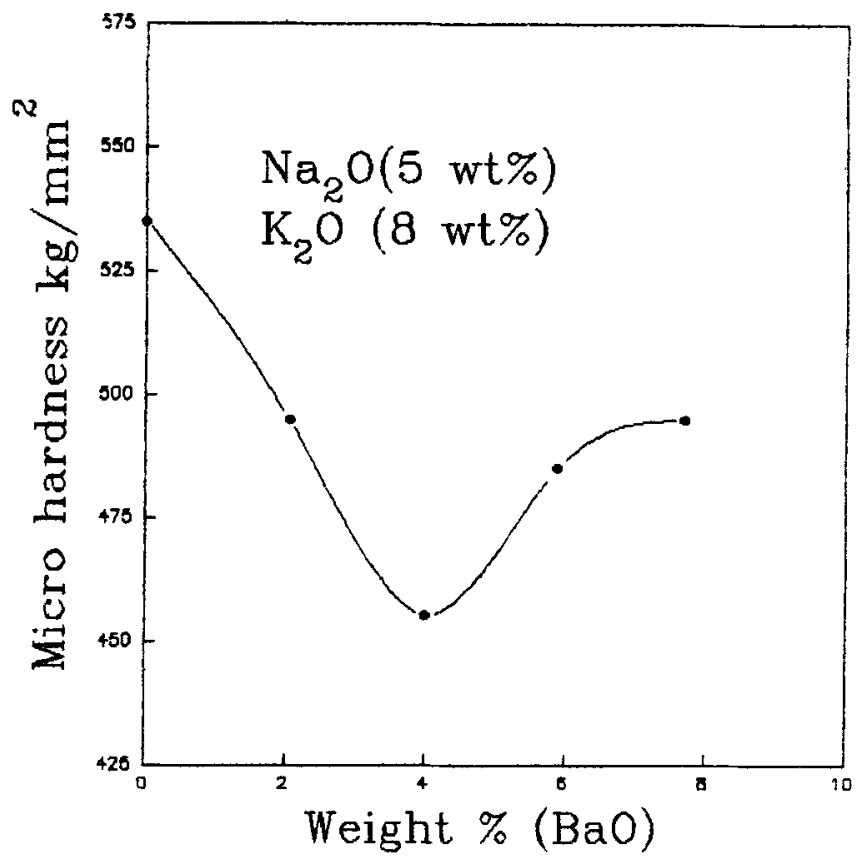

Figure 5. Micro hardness as a function of $\mathrm{BaO}$ content in glass samples with $5 \mathrm{wt} \%$ of $\mathrm{Na}_{2} \mathrm{O}$ and $8 \mathrm{wt} \% \mathrm{~K}_{2} \mathrm{O}$.

micro hardness of the glass at lower concentrations up to $4 \mathrm{wt} \%$, followed by a rise in the micro hardness with increasing concentrations of $\mathrm{BaO}$.

From the above observation it is clear that in all the cases the micro hardness of the glass increases at higher concentrations of the modifier ions but this effect was more pronounced when the concentration of $\mathrm{Na}_{2} \mathrm{O}$ was increased. It is observed that when alkali and/or alkaline earth oxides react with $\mathrm{SiO}_{2}$ to form the glass, the $\mathrm{Si}-\mathrm{O}-\mathrm{Si}$ network is broken depending upon the concentration of modifier ions which decreases the viscosity of the silicate glass compared to fused silica. This decrease in the viscosity makes ions more mobile, thereby increasing the probability of nucleation and growth of crystallites (devitrification). Consequently, the glass matrix becomes more rigid through the modification in site occupation and offers higher resistance to penetration, hence the increase in micro hardness.

The composition which contained only $\mathrm{K}_{2} \mathrm{O}$ yielded clear transparent glass. On the other hand, a complete absence of potassium resulted in a glass with multiple cracks. This result suggests that the absence of potassium leads to the generation of strains that are in excess of the breaking strain of the glass. This is in conformity with micro hardness measurements. The glass with high content of $\mathrm{Na}_{2} \mathrm{O}$ exhibited quite high value (about $550 \mathrm{~kg} / \mathrm{mm}^{2}$ ) of micro hardness, thereby making it more susceptible for cracking. In addition, increase in the $\mathrm{Na}_{2} \mathrm{O}$ content above $5 \mathrm{wt} \%$ was found to give rise to the introduction of bubbles in the GM seals. Excess
Table 1. Typical composition of the glass suitable for GM seal.

\begin{tabular}{lc}
\hline Constituent & Weight \% (g) \\
\hline $\mathrm{SiO}_{2}$ & 52.43 \\
$\mathrm{Na}_{2} \mathrm{O}$ & 04.85 \\
$\mathrm{~K}_{2} \mathrm{O}$ & 07.77 \\
$\mathrm{BaO}$ & 03.88 \\
$\mathrm{PbO}$ & 31.07 \\
\hline
\end{tabular}

$\mathrm{Na}_{2} \mathrm{O}$ in lead glass also has been reported to be detrimental for lead ion stability (Lehman 1992). However, the addition of sodium oxide in appropriate amount was found to be necessary for lowering the glass working temperature for making a seal and that of $\mathrm{BaO}$ for improving its insulation. The glass powder having typical composition as shown in table 1 was found to be suitable for the purpose of GM seals. The seals prepared in this case withstood pressure of $1.2 \times 10^{4} \mathrm{psi}$ and vacuum $\sim 10^{-8}$ Torr.

\section{Conclusions}

Lead silicate glass powder suitable for GM seals has been synthesized following both the nitrate and carbonate routes. The softening temperature in the former case was found to be slightly higher. The study shows that higher content of the modifier ions leads to some devitrification in the glass making them unsuitable for fabricating compression type seals. Sodium oxide content higher than $5 \mathrm{wt} \%$ in absence of $\mathrm{K}_{2} \mathrm{O}$ in the glass, has been found to give rise to the introduction of bubbles in the seals.

\section{Acknowledgements}

The authors wish to thank Dr V C Sahni for his encouragement and keen interest in the work. They would like to thank Mr B K Shah for providing micro hardness measurement facility. The valuable technical assistance received from. Messrs J K Panchal, H Y Bodari, P A Wagh and B B Pandare is gratefully acknowledged.

\section{References}

Anderson L P, Grusell E and Berg S 1979 J. Phys. E12 434

Bandhopadhyay N, Tamhankar S S and Kirschner M J 1989 Eur. Pat. Appl. EP 311308

Donald I W 1993 J. Mater. Sci. 28284

Holland L 1966 The properties of glass surfaces (London: Chapman and Hall) p. 59

Lehman R L 1992 J. Am. Ceram. Soc. 752194 
Liu L 1993 Z. Phys. (B) Condensed Matter 90393

Mckee B T A, Linhananta A and Stewart A T $1988 \mathrm{Nucl}$. Instrum. Meth. A273 911

Muller E, Heide K and Zanotto E D 1993 J. Non-Cryst. Solids 15556

Shrikhande V K et al 1997 MRSI Annual General Meeting, $B A R C$, Mumbai

Shrikhande V K, Mirza T, Sawant B B, Muthe K P, Ravindran
P V, Kothiyal G P and Sahni V C 1998 Indian J. Pure \& Appl. Phys. (in press)

Tabor D 1996 Philos. Mag. A74 1207

Tashiro H and Okuda K 1987 Jpn Kokai Tokkyo Koho JP 62 434

Thomas G L and Sircer A 1987 GE Co. US Patent 77081

Wang P W and Zhang L 1996 J. Non-Cryst. Solids 194129

Wiza J L 1979 Nucl. Instrum. \& Meth. 62587 